$\xi=-1$

\title{
A Systematic Literature Review of the Barriers to Job Placement for Person with Disabilities
}

\author{
Nurfarhani Farah Anuaruddin', Rabeatul Husna Abdull Rahman ${ }^{2 *}$, Salwa Abdul Patah, Azra Ayue Abd Rahman ${ }^{3}$, \\ Muhammad Ashfaq ${ }^{4}$ \\ ${ }^{1,2,3,4}$ Department of Human Resource Development, Faculty of Management, Universiti Teknologi Malaysia \\ * Corresponding author E-mail:husna@management.utm.my
}

\begin{abstract}
People often fail to realize that the disabled population is an important but largely untapped human resource. Prejudices and misconceptions about person with disabilities' ability to perform and compete in the open market are likely to be the cause. This research endeavor provides an overview of some of the factors that contributes for low ratio of job placements for persons with disabilities. Study about such factors is imperative so as to improve understanding regarding this phenomenon and increase employment opportunities for person with disabilities. Review of literature is carried out to highlight the barriers to job placement for persons with disabilities. Some of the barriers highlighted in this study are the attitude of the employers towards the hiring of persons with disabilities, job demand, and attitude of disabled persons. This paper concludes that more training and awareness programs should be conducted to educate employers about human resource policies, practices and strategies for persons with disabilities to improve their participation in the mainstream workforce. This research will have useful implications for the policy makers for incorporating untapped human resource in the form of persons with disabilities.
\end{abstract}

Keywords: Persons with Disabilities; Job Placement; Employment; Labour Market

\section{Introduction}

The inclusion of person of disabilities in the labour market has been the attention of many countries. This is because the participation rate of person with disabilities in the mainstream labour market is not as substantial as compared to non-disabled counterparts (1-2). Person with disabilities are generally considered as the marginalized population whereby they are systematically being excluded socially and economically (1-3). $80 \%$ of person with disabilities live in developing countries and are among the very poorest (4). The inclusion of person with disabilities in the labour market not only would improve their conditions but also may be one of the solutions for the problem of ageing labour market population particularly in developed countries (1). Although many countries such as Thailand has allocated a certain percentage of vacancies for person with disabilities, these job vacancies however could not be filled due to various factors such as lack of qualified disabled candidate (5). Various other causes for the barriers to job placement of person with disabilities have been discussed widely in the literature. However most of the past studies were based on the findings obtained from the non-disabled respondents i.e. employers.

\section{Literature Review}

First thing first, it is important to know that stigmatized people often be the target of exclusion by the society. Stigmatized people, basically consist of people who possess less social power, have low status in among the society and underserving of the rights as other society members such as people of colour, obese, religious group, ethnics, and even disabled people (6). As stigmatized people are considered as individuals who are lacking in human characteristics and sometimes considered as 'infrahumans', they are often excluded by groups or society which think that they are radically different from the others (7). One of the groups which are impotent to social exclusion as suggested by Sloane (8) is people with disabilities. As a result, they are socially excluded and the endeavours to include them in the mainstream society are still not achieved especially for people with mental and physical disabilities (9).

A study conducted by Yfantopoulos (10) for the Disability and Social Exclusion in European Union has revealed several findings which are not surprising to be comprehended regarding this matter and context. In terms of disability benefits, despite most of disabled people received the benefits awarded for them based on severity of their disabilities, $93 \%$ of them still consider that the benefits they received are inadequate because it is insufficient to cover their basic necessities. Although they may receive special benefits due to their disabilities, PWD are still in the group of people who receive low income and face difficulties in fulfilling their needs as most of them needs to cover for the extra costs due to their conditions, which makes them to consider themselves as in a poor or very poor situation.

Besides that, in terms of education, one of the reasons why disabled people are being socially excluded is because of the lack of education they receive from the beginning. This is caused by the limited opportunities for disabled children to participate in the mainstream education (11) due to lack of support in the academic and extracurricular activities (10), denial of education from families or even the society (12), underfunded institutions and unskilled teachers (11). 
Furthermore, in terms of unemployment, as it is related to social exclusion, only $30.5 \%$ of the disabled population are employed and $20.8 \%$ of the disabled people are found to be unemployed due to several factors including issues on the workplace and employers, lack of psychological support, and personal factors such as severity of their disabilities and also their education level (10). One of the reasons of the low employment rate among disabled people is due to low job satisfaction compared to other nondisabled employees (13) and lack of education which narrow down their options for employment (12). Another impeding factor to employment for them is the losing of their income support if they are able to have a job (10).

Besides that, there is also a list of other contributing factors of exclusion faced by disabled people as found by Yfantopoulos (10) which are; lack of access to health and social services, denial of citizenship rights and barriers to public administrations (11), lack of access of social environment, lack of access on ICT, inadequate social services provided for them (11), stigmatization (14), inadequate training and education system, and many more. These factors of exclusion are mostly triggered due to negative social attitudes and prejudice by others (15), barriers in communication, barriers in physical and architectures and also financial. Burchardt (13) also stated that lack of accessibilities, lack of chances to socialize and increased rate of poverty among disabled people may be the contributing factors of their dissatisfaction of life.

On a bigger scope, the effect of exclusion in terms of societal, community, relationship and individual towards disabled people will cause them to have less access to education, poor health and wellbeing, less participation in the economic, social and community, higher rate of poverty and dependency on others (16). According to United Nations (17), disabled people often face discrimination and marginalisation, and (18) too has stated that people with disabilities are the workforce which is being marginalized from employment as compared to other populations. Disabled people are being marginalised due to their impairments and also the environmental obstacles which cause them to be disempowered and overprotected. However, (18) also stated that the cost of marginalizing and disempowering disabled people as well as letting them to stay dependent are high, not only on people they are depending on, but also on the general society. On the other hand, regardless of the impairments, it will be very advantageous for the society if disabled people are empowered as they will help to contribute socially and economically as well as being more independent (18).

\section{Methodology}

A systematic literature search in several databases including SCOPUS, Wiley, Science Direct and Emerald was conducted. We used several keywords such as 'employment or employability challenges or barriers and person with disabilities'. The literature search resulted in 5367 studies which were then screened for duplicates and eligibility. We finally selected 27 articles for review. All except one of the studies were published from 2000 onwards. A considerable number of these studies were qualitative in nature which includes case study, interview and focus group. Only five studies used quantitative approach. In terms of their research populations, majority of the studies had involved employers/policymakers. A mere five studies had involved person with disabilities. This suggests that most of the past studies have focused on the barriers to hiring person with disabilities from the employers' perspectives rather than from the disabled persons' point of view.

\section{Results and Findings}

The research findings can be categorised into three: (a) employers' attitude, (b) person with disabilities' attitude, and (c) job demand.

\subsection{Barriers to Job Placement of Person with Disabili- ties}

\subsubsection{Employers' Attitude}

Review of relevant literature revealed that person with disabilities face numerous employment barriers. The main cause identified is the employers' attitude towards hiring disabled person. Employers have a negative perception towards person with disabilities whereby they are concerned that person with disabilities could not perform the task (19-22). Past literature shows that attitude of managers impact the hiring of PWDs (23-25) found that attitude influences intention, while in turn, intention predicts behaviour. In the case of hiring decisions for person with disabilities, the employer must first have a favorable attitude toward hiring person with disabilities before this attitude can translate to intention to hire person with disabilities. Some recent studies suggest that employers usually think that employees with disabilities have lower productivity, higher absenteeism, lack the necessary skills or require greater supervision compared to those without disabilities (26-27). While on the other hand employers with experience working with person with disabilities have more favourable attitudes toward employees with disabilities, and display greater willingness to hire other individuals with disabilities (28-29).

Gröschl (30) and (20,27) suggest that employers are uneducated and inexperienced about person with disabilities; hence they have limited awareness, and understanding about person with disabilities. This resulted in the stigma towards disability which can have a lot of negative effects for those who are being stigmatized, including discrimination and exploitation of person with disabilities at work (31). For example, person with disabilities are systematically excluded by the hotel industry. According to Gröschl (30), employers have a preference for physical attractiveness which is discriminatory for person with disabilities. Besides, employers are concerned about the additional costs that might incur as a result of hiring disabled employees $(20,27)$. Employers also believe that their corporate culture is not welcoming for person with disabilities (32-33) and that their workplace lacks the facilities and are not conducive for person with disabilities (34). They are concerned about co-workers attitudes towards person with disabilities (33) and the ability of their supervisors in managing person with disabilities (20). It is also evident from the literature that employers fear of legal liability $(22,27)$.

\subsubsection{Person with Disabilities' Attitude}

Another important barrier is the attitude of person with disabilities. According to Ali et al., (32) the causes for low employment of person with disabilities are their lack of skill for available jobs, and their lack of effort and optimism about securing a job. This barrier is pertinent for those with low education and training level. There are also several reasons that job preferences of person with disabilities may differ from those of person without disabilities. First, they may desire flexibility in work arrangements to deal with health or mobility conditions. As noted by Schur: "many people with disabilities experience fatigue and other health problems, making it difficult to work a full 40 -hour work week on a regular, predictable basis. Those with mobility impairments may have transportation problems, making flexible contingent work more attractive" (35). Person with disabilities are in fact more likely to be part-time and temporary employees, although they are not more likely to be in jobs with flexible hours (36). The preferences of person with disabilities may reflect personal and family concerns (e.g., health issues, transportation difficulties, therapy schedules, medical appointments, need for personal assistance, and reliance on family members). The need to accommodate non work concerns such as health and mobility issues may lead person with disabilities to prefer jobs with greater flexibility, while their lower incomes and greater likelihood of living alone may lead them to prefer jobs with high income and job security (32). 


\subsubsection{Job Demand}

Low employment and the financial crisis are critical examples of contextual factors that significantly impact employment outcomes for person with disabilities. As per Gröschl (30), there are less job demand for person with disabilities with further limits their chances of being employed in the labour market. The recession has a disproportionate impact on person with disabilities, with the number of employed person with disabilities declining at a rate of about two to three times that of person without disabilities (3738). Employers' stigmatization towards person with disabilities is also a critical factor that resulted in the decrease of job offer for person with disabilities (32).

\section{Conclusion}

The present study aimed to contribute to a better understanding of some of the variables that hinder the employability of the persons with disabilities. Review of literature revealed some important factors that are hindering the disable people to be included in the mainstream workforce. Exclusion of persons with disabilities from the job market has important ramifications. Not also their potential remains untapped but also the socioeconomic condition of the disable persons also deteriorates. Exclusion from the job market has negative impact on the psychological well-being of the PWD's. The barriers highlighted in the present research need some corrective measures on part of public as well as private sector.

Among the roles that could be played by the government are to educate employers about person with disabilities via training programs, seminars, and conferences. This effort not only would improve employers' understanding about person with disabilities but also educate employers about the subsidies and financial incentives from hiring person with disabilities, and also protection from legal risks (27). Apart from training and education, it is imperative that more actions are taken to remove stigmatization and negative perceptions towards disability (30). This could be done by imposing regulations that would prevent and minimize employers' discriminatory human resource practices such as in hiring disabled candidates (39). Forced quota system (40) may also improve the employment of person with disabilities, which has been successful in South Korea (41).

Educated and informed employers are possibly more likely to offer employment opportunities that are suitable for person with disabilities. It is critical that organization practises fair employment, equal employment and non-discriminatory policies for person with disabilities (39). To further support the employment and retention of person with disabilities, employers may want to consider providing a friendlier human resource policies and practices that are conducive for person with disabilities, such as flexible work schedule (20). Integration between co-workers and person with disabilities are also essential in developing a welcoming workplace for both parties (42).

Last but not least, Jans et al., (43) suggest that person with disabilities should be open about their disability and to discuss areas which they can contribute with their employers. They should also change their attitudes - develop their skills to increase their employability for available jobs, network with successfully employed person with disabilities and seek jobs that are in line with their needs.

Future research in this area can explore the role of NGO's in uplifting of persons with disabilities. Moreover the research work can be done on exploring some of the highly demanded job skills that can be easily imparted to the persons with disabilities.

\section{Acknowledgement:}

This research work is supported by Universiti Teknologi Malaysia. The authors wish to thank Universiti Teknologi Malaysia for sponsoring this publication (Vote No. 11J74).

\section{References}

[1] Powers, T. (2008). Recognizing ability: The skills and productivity of persons with disabilities. Literature review. Switzerland: International Labour Office, Geneva.

[2] Licona, G. H. (2001). Disability and the labor market in Latin America. Annual conference of the Inter-American Development Bank. Chile. Retrieved from http://www.disabilityworld.org/0708 01/employment/labor2.shtml

[3] Islam, M. R. (2015). Rights of the people with disabilities and social exclusion in Malaysia. International Journal of Social Science and Humanity, 5(2), 171

[4] World Bank. (2005). Development outreach: Disability and inclusive development. Washington, DC: World Bank. Retrieved from http://documents.worldbank.org/curated/en/805041468314726419/ pdf/4062010color.pdf

[5] ILO. (2003). Employment of People with Disabilities, the Impact of Legislation: Asia and the Pacific. Retrieved from http://www.ilo.org/wcmsp5/groups/public/---asia/---robangkok/documents/publication/wcms_bk_pb_90_en.pdf

[6] Major, B. \& Eccleston, C. P. (2005). Stigma and Social Exclusion In D. Abrams, M. A. Hogg and J. M. Marques. (Ed.), The social psychology of inclusion and exclusion (pp. 63-87). New York: Psychology Press.

[7] Leyens, J. P., Paladino, P. M., Rodriguez-Torres, R., Vaes, J., Demoulin, S., Rodriguez-Perez, A. \& Gaunt, R. (2000). The Emotional Side of Prejudice: The Attribution of Secondary Emotions to in groups and Outgroups. Personality and Social Psychology Review, 4(2), 186-197.

[8] Sloane, P. J. \& Jones, M. K. (2012). Disability and Social Exclusion In G. Parodi and D. Sciulli. (Ed.), Social Exclusion: Short and Long Term Causes and Consequences (pp. 127-148). Heidelberg: Physica-Verlag HD.

[9] Coughlan, S. (2010). Disabled are socially excluded says Scope survey. BBC News education and family correspondent. Retrieved from http://www.bbc.com/news/education-11139534

[10] Yfantopoulos, Y. (2002). Disability and Social Exclusion in the European Union: Time for change, tools for change. Final study report, June 2002. Retrieved from http://sid.usal.es/idocs/F8/FDO7040/disability_and_social_exclusio n_report.pdf

[11] National Disability Strategy Consultation Report. (2009). SHUT OUT: The Experience of People with Disabilities and their Families in Australia. Retrieved from https://www.dss.gov.au/sites/default/files/documents/05_2012/nds_ report.pdf

[12] Tobias, E. I. \& Mukhopadhyay, S. (2017). Disability and Social Exclusion. Psychology and Developing Societies. 29(1), 22-43.

[13] Burchardt, T. (2003). Being and becoming: Social exclusion and the onset of disability. Retrieved from http://eprints.lse.ac.uk/28310/1/CASEreport21.pdf

[14] European Disability Forum. (2017). International Youth Day 2017: Voices of Young People with Disabilities. Retrieved from http://www.edf-feph.org/newsroom/news/international-youth-day2017-voices-young-people-disabilities

[15] Veres, O., Ujhelyi, S. \& Szabó, D. (2013). Social exclusion of handicap people in Hungary. Retrieved from http://netaware.ue.katowice.pl/wpcontent/uploads/2013/03/National-report-HungaryHandicapped.pdf

[16] Appleton-Dyer, S. \& Field, A. (2014). Understanding the factors that contribute to social exclusion of disabled people. Rapid review for Think Differently. Retrieved from https://www.odi.govt.nz/assets/Guidance-and-Resourcesfiles/Understanding-the-factors-that-contribute-to-the-exclusion-ofdisabled-people-November-2014.pdf

[17] United Nations \& Byrnes, A. (2007). From Exclusion to Equality: Realizing the Rights of Persons with Disabilities: Handbook for Parliamentarians on the Convention on the Rights of Persons with Disabilities and Its Optional Protocol: United Nations, Office of 
the High Commisioner for Human Rights.

[18] Disabled World. (2012). The Costs of Marginalizing People with Disabilities. Retrieved from https://www.disabledworld.com/editorials/marginalizing.php

[19] Jasper, C. R. \& Waldhart, P. (2012). Retailer perceptions on hiring prospective employees with disabilities. Journal of Retailing and Consumer Services, 19(1), 116-123.

[20] Houtenville, A. \& Kalargyrou, V. (2012). People with disabilities: Employers' perspectives on recruitment practices, strategies, and challenges in leisure and hospitality. Cornell Hospitality Quarterly, 53(1), 40-52.

[21] Henry, A. D., Petkauskos, K., Stanislawzyk, J. \& Vogt, J. (2014). Employer-recommended strategies to increase opportunities for people with disabilities. Journal of Vocational Rehabilitation, 41(3), 237-248.

[22] Kocman, A., Fischer, L. \& Weber, G. (2017). The Employers' perspective on barriers and facilitators to employment of people with intellectual disability: A differential mixed-method approach. Jour nal of Applied Research in Intellectual Disabilities, 31(1), 120-131.

[23] Ang, M. C. H., Ramayah, T. \& Amin, H. (2015). A theory of planned behavior perspective on hiring Malaysians with disabilities. Equality, Diversity and Inclusion, 34(3), 186-200.

[24] Fraser, R. T., Johnson, K., Hebert, J., Ajzen, I., Copeland, J., Brown, P. \& Chan, F. (2010). Understanding employer's hiring intentions in relation to qualified workers with disabilities: Preliminary findings. Journal of Occupational Rehabilitation, 20(4), 420426.

[25] Kim, M. S. \& Hunter, J. E. (1993). Attitude-behavior relations: A meta-analysis of attitudinal relevance and topic. Journal of communication, 43(1), 101-142.

[26] Domzal, C., Houtenville, A. \& Sharma, R. (2008) Survey of Employer Perspectives on the Employment of People with Disabilities: Technical Report, Prepared under Contract to the Office of Disability and Employment Policy. US Department of Labor, CESSI, McLean. $\quad$ Retrieved from https://www.dol.gov/odep/research/SurveyEmployerPerspectivesE mploymentPeopleDisabilities.pdf

[27] Kaye, H. S., Jans, L. H. \& Jones, E. C. (2011). Why don't employers hire and retain workers with disabilities? Journal of Occupational Rehabilitation, 21(4), 526-536.

[28] Hernandez, B., McDonald, K., Divilbiss, M., Horin, E., Velcoff, J. \& Donoso, O. (2008). Reflections from employers on the disabled workforce: Focus groups with healthcare, hospitality and retail administrators. Employee Responsibilities and Rights Journal, 20(3), 157-164.

[29] Luecking, R. G. (2008). Emerging employer views of people with disabilities and the future of job development. Journal of Vocational Rehabilitation, 29(1), 3-13.

[30] Gröschl, S. (2007). An exploration of HR policies and practices affecting the integration of persons with disabilities in the hotel industry in major Canadian tourism destinations. International Journal of Hospitality Management, 26(3), 666-686.

[31] Tiun, L. T. \& Khoo, S. L. (2013). Challenges Faced by Malaysians with Disabilities in the World of Employment. Retrieved from https://www.researchgate.net/publication/271123597_Challenges_F aced_by_Malaysians_with_Disabilities_in_the_World_of_Employ ment

[32] Ali, M., Schur, L. \& Blanck, P. (2011). What types of jobs do people with disabilities want? Journal of Occupational Rehabilitation. 21(2), 199-210.

[33] Vornholt, K., Uitdewilligen, S. \& Nijhuis, F. J. N. (2013). Factors affecting the acceptance of people with disabilities at work: A literature review. Journal of Occupational Rehabilitation, 23(4), 463475.

[34] Sanchez-Gordon, S., Mejía, M. \& Luján-Mora, S. (2017). Model for adjusting workplaces for employees with visual and hearing disabilities. Paper presented at the 2017 4th International Conference on eDemocracy and eGovernment, ICEDEG 2017.

[35] Schur, L. A. (2003). Barriers or opportunities? The causes of contingent and part-time work among people with disabilities. Industrial Relations, 42(4), 589-622.

[36] Presser, H. B. \& Altman, B. (2002). Work shifts and disability: a national view. Monthly Lab. Rev., 125, 11.

[37] Fogg, N. P., Harrington, P. E. \& McMahon, B. T. (2011). The underemployment of persons with disabilities during the Great Recession. The Rehabilitation Professional, 19(1), 3-10.

[38] Kaye, H. S. (2010). The impact of the 2007-09 recession on workers with disabilities. Monthly Labor Review, 133(10), 19-30.
[39] Markel, K. S. \& Barclay, L. A. (2009). Addressing the underemployment of persons with disabilities: Recommendations for expanding organizational social responsibility. Employee Responsibilities and Rights Journal, 21(4), 305-318.

[40] Garbat, M. (2013). European policy models of employment of people with disabilities. Journal of Social Research and Policy, 4(1), 47-63.

[41] Nazarov, Z., Kang, D. \& von Schrader, S. (2015). Employment quota system and labour market outcomes of individuals with disabilities: Empirical evidence from South Korea. Fiscal Studies, 36(1), 99-126

[42] Kulkarni, M. \& Lengnick-Hall, M. L. (2011). Socialization of people with disabilities in the workplace. Human Resource Management, 50(4), 521-540.

[43] Jans, L. H., Stephen Kaye, H. \& Jones, E. C. (2012). Getting hired: Successfully employed people with disabilities offer advice on disclosure, interviewing, and job search. Journal of Occupational Rehabilitation, 22(2), 155-165. 